\title{
The genetics of eye disorders in the dog
}

\author{
Cathryn S Mellersh
}

\begin{abstract}
Inherited forms of eye disease are arguably the best described and best characterized of all inherited diseases in the dog, at both the clinical and molecular level and at the time of writing 29 different mutations have been documented in the scientific literature that are associated with an inherited ocular disorder in the dog. The dog has already played an important role in the identification of genes that are important for ocular development and function as well as emerging therapies for inherited blindness in humans. Similarities in disease phenotype and eye structure and function between dog and man, together with the increasingly sophisticated genetic tools that are available for the dog, mean that the dog is likely to play an ever increasing role in both our understanding of the normal functioning of the eye and in our ability to treat inherited eye disorders. This review summarises the mutations that have been associated with inherited eye disorders in the dog.
\end{abstract}

\section{Lay summary}

Inherited forms of eye disease are arguably the best described and best characterized of all inherited diseases in the dog, at both the clinical and molecular level and at the time of writing 29 different mutations have been documented in the scientific literature that are associated with an inherited ocular disorder in the dog. The dog has already played an important role in the identification of genes that are important for ocular development and function as well as emerging therapies for inherited blindness in humans. Similarities in disease phenotype and eye structure and function between dog and man, together with the increasingly sophisticated genetic tools that are available for the dog, mean that the dog is likely to play an ever increasing role in both our understanding of the normal functioning of the eye and in our ability to treat inherited eye disorders. This review summarises the mutations that have been associated with inherited eye disorders in the dog.

\section{Introduction}

Inherited forms of eye disease are arguably the best described and best characterized of all inherited diseases in the dog, at both the clinical and molecular level. At the time of writing 29 different mutations have been documented in the scientific literature that are associated with an inherited ocular disorder in the dog (Table 1).

Correspondence: cathryn.mellersh@aht.org.uk

Animal Health Trust, Lanwades Park, Kentford, Suffolk CB8 7UU, UK
Several more conditions have been described very well at the genetic and clinical level although their causal mutations remain elusive; however the genetic basis of many of these will undoubtedly be unraveled over the coming years, thanks to the increasingly sophisticated genetic resources that are now available for the dog.

Why have so many inherited eye disorders been described in the dog? A principal reason is that the eye is very accessible, and much of it can be examined in detail using non-invasive techniques, making it relatively easy to detect abnormalities, even if they do not impair vision significantly. There are clinical screening schemes in place in many countries that offer dog breeders the opportunity to screen their dogs, ideally before they are bred from, for disorders known to be inherited in their breed. One such scheme is the British Veterinary Association/Kennel Club/International Sheep Dog Society Eye Scheme that operates in the United Kingdom (http://www.bva.co.uk/ canine_health_schemes/Eye_Scheme.aspx). This scheme covers 11 inherited eye disorders in over 50 breeds of dog. The European College of Veterinary Ophthalmologists (ECVO) Scheme (http://www.ecvo.org/) is in use in seven European countries, and individual ECVO Diplomates work in accordance with the scheme in other countries to control presumed inherited diseases of the eye and its adnexa. In the United States the Orthopedic Foundation for Animals (OFA) and the American College of Veterinary Ophthalmologists (ACVO) maintain a joint Eye Certification Registry (ECR). OFA Eye Certification Registry exams are ophthalmic examinations, performed by 
Table 1 Genes associated with inherited eye disorders in the domestic dog

\begin{tabular}{|c|c|c|c|c|}
\hline Disease & $\begin{array}{l}\text { Locus or } \\
\text { abbreviation }\end{array}$ & Gene & Breed & Reference \\
\hline Cone-rod dystrophy & CRD3 & ADAM9 & Glen of Imaal terrier & {$[53,54]$} \\
\hline Primary open angle glaucoma & POAG & ADAMTS10 & Beagle & {$[147]$} \\
\hline Primary lens luxation & PLL & ADAMTS17 & Multiple, mainly terrier breeds & {$[129,132]$} \\
\hline Rod cone degeneration & RCD4 & C2orf71 & Gordon Setter, Irish Setter, Tibetan Terrier & [30] \\
\hline Generalised progressive retinal atrophy & gPRA & CCDC66 & Schappendoes & {$[28]$} \\
\hline Progressive retinal atrophy & PRA & CNGB1 & Papillon & {$[15,17]$} \\
\hline Cone degeneration & $C D$ & CNGB3 & Alaskan malamute & [68] \\
\hline Cone degeneration & $C D$ & CNGB3 & German shorthaired pointer & [69] \\
\hline $\begin{array}{l}\text { Dwarfism with retinal dysplasia (oculoskeletal } \\
\text { dysplasia) }\end{array}$ & DRD2 (OSD2) & COL9A2 & Samoyed & [90] \\
\hline $\begin{array}{l}\text { Dwarfism with retinal dysplasia (oculoskeletal } \\
\text { dysplasia) }\end{array}$ & DRD1 (OSD1) & COL9A3 & Labrador retriever & {$[90]$} \\
\hline Hereditary cataract & $\mathrm{HC}, \mathrm{EHC}$ & HSF4 & $\begin{array}{l}\text { Staffordshire bull terrier, Boston terrier, French } \\
\text { bulldog }\end{array}$ & [103] \\
\hline Hereditary cataract & $\mathrm{HC}$ & HSF4 & Australian Shepherd & {$[107]$} \\
\hline Collie eye anomaly & CEA & NHEJ1 & Collies & [91] \\
\hline Cone-rod dystrophy & & NPHP4 & Standard wirehaired dachshund & [49] \\
\hline Photoreceptor dysplasia & PD & PDC & Miniature schnauzer & [13] \\
\hline Rod cone dysplasia & RCD1 & PDE6B & Irish setter & {$[2]$} \\
\hline Rod cone dysplasia & RCD1 & PDE6B & Sloughi & {$[3]$} \\
\hline Rod cone dysplasia & RCD3 & PDE6A & Cardigan Welsh corgi & {$[4]$} \\
\hline Progressive rod-cone degeneration & PRCD & PRCD & Multiple breeds & [23] \\
\hline Rod cone dysplasia & RCD2 & RD3 & Collie & {$[7]$} \\
\hline Autosomal dominant progressive retinal atrophy & ADPRA & $\mathrm{RHO}$ & English mastiff & [24] \\
\hline Congenital stationary night blindness & CSNB & RPE65 & Briard & {$[58,59]$} \\
\hline X-linked progressive retinal atrophy & XLPRA2 & $R P G R$ & Mixed breed dogs & [18] \\
\hline X-linked progressive retinal atrophy & XLPRA1 & $R P G R$ & Siberian Husky, Samoyed & {$[18]$} \\
\hline Cone-rod dystrophy & CORD1 (CRD4) & $R P G R I P$ & Dachshunds & [38] \\
\hline Early retinal degeneration & ERD & STK38L & Norwegian elkhound & [11] \\
\hline Canine multifocal retinopathy & CMR1 & $\begin{array}{l}\text { VMD2/ } \\
\text { BEST1 }\end{array}$ & $\begin{array}{l}\text { Great Pyrenees, English Mastiff, and Bullmastiff } \\
\text { dogs }\end{array}$ & [74] \\
\hline Canine multifocal retinopathy & CMR2 & $\begin{array}{l}\text { VMD2/ } \\
\text { BEST1 }\end{array}$ & Coton de Tulears & [74] \\
\hline Canine multifocal retinopathy & CMR3 & $\begin{array}{l}\text { VMD2/ } \\
\text { BEST1 }\end{array}$ & Lapponian Herder & [75] \\
\hline
\end{tabular}

ACVO Diplomates, to assess dogs for the presence or absence of observable hereditary ocular disease. Dogs with normal exam results receive OFA eye certification numbers valid for one year. The three schemes listed above, and other comparable schemes in place around the world, differ incrementally from one another in the precise ways in which they are operated, but they all serve to document and register dogs affected with, and free from, inherited eye diseases. Each dog that is clinically examined under any of these schemes receives a certificate on which the results of the examination are recorded and the findings are also recorded in the relevant registry/database, thus providing a wealth of data regarding the clinical characteristics and incidence of inherited eye disorders in different breeds of domestic dog.

\section{Review}

Diseases of the retina

Inherited forms of retinal disease are among the best clinically and genetically characterized genetic conditions in the dog. Retinal disorders can be categorized in various ways and the way in which they have been 
described in this review, which is summarized in Figure 1, is certainly not the only way to partition them. Most methods of classification will, however, broadly take into account the typical stage of development or age of onset of the disease, the cells that are typically affected and whether the disease becomes progressively severe during the dog's lifetime or whether it is more or less stationary. Here the retinal disorders have been broadly divided into two main categories; the degenerative conditions where the retina develops normally and then degenerates during the dog's lifetime and the developmental or dysplastic diseases in which the retina develops abnormally. It should be stressed, however, that categorising all retinal disease into these two broad forms is inevitably an over simplication in some cases, and that a minority of retinal diseases have both dysplastic and degenerative characteristics.

\section{Degenerative retinal disorders}

The majority of retinal diseases that have been described in the dog are degenerative conditions. Some degenerative conditions are characterized by an inevitable increase in severity over time, invariably culminating in complete loss of vision, whereas other conditions are characterized by a pathology that does not deteriorate significantly throughout life. These two broad clinical categories of disease are described below under the headings progressive and stationary respectively.

\section{Progressive retinal disorders}

Progressive retinal atrophy (PRA) and cone-rod dystrophy (CRD) are collective terms for two broad forms of progressive, bilateral degenerative diseases that affect the retinal photoreceptor cells.

\section{Progressive retinal atrophy}

In general, PRAs are characterized by initial loss of rod photoreceptor function followed by that of the cones and for this reason night blindness is the first significant clinical sign for most dogs affected with PRA. Visual impairment in bright light invariably follows, accompanied by characteristic changes to the fundus that are visible upon ophthalmoscopic investigation. Typical changes include attenuation of the blood vessels of the retina, increased reflectivity of the tapetal layer as a result of retinal thinning and atrophy of the optic disc. In many dogs secondary cataracts develop, which might become

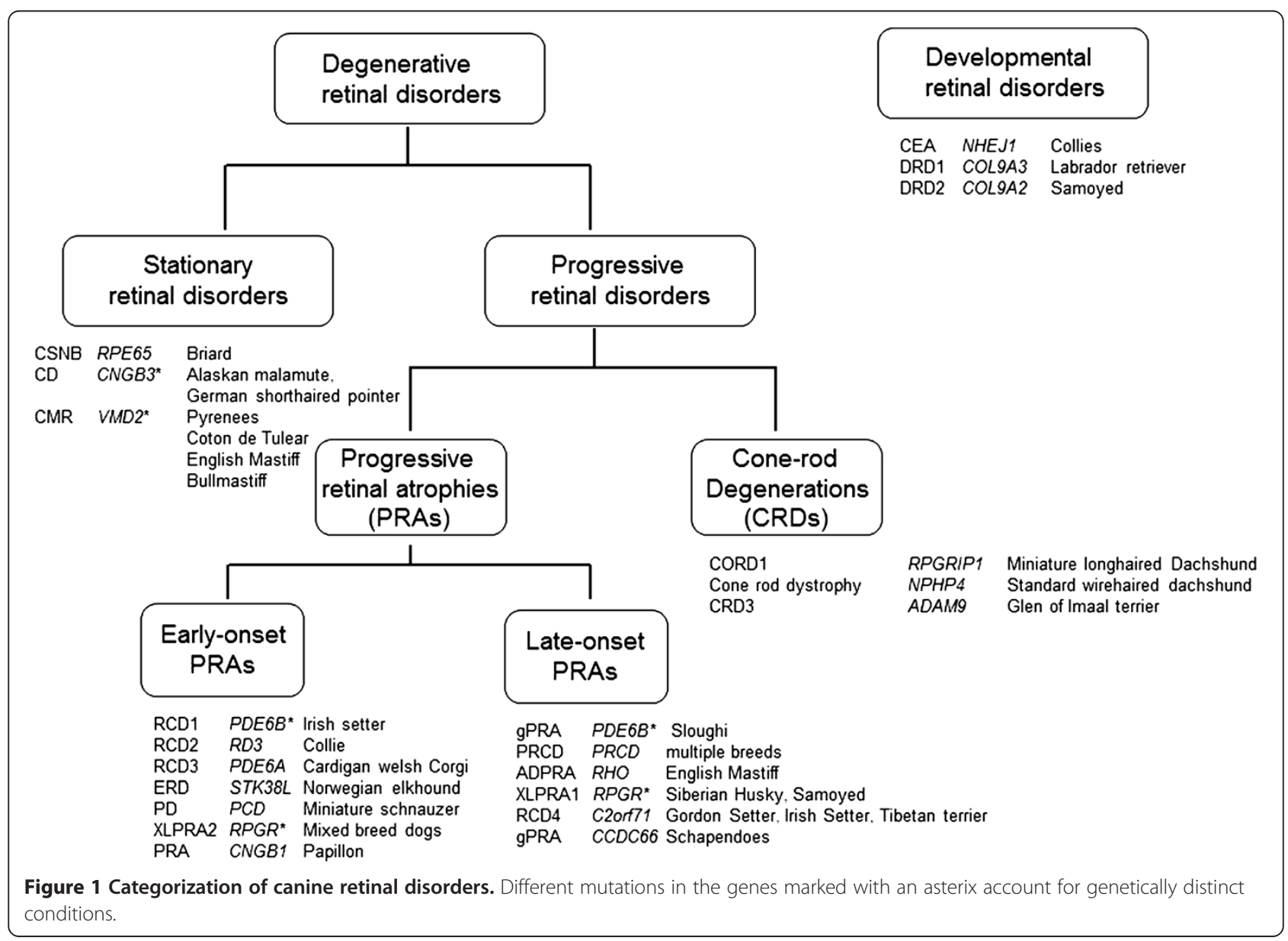


extensive enough to obscure the retina and require the use of electroretinography (ERG) for diagnosis. Whereas most dogs show the same ophthalmoscopic abnormalities the age at which these abnormalities develop varies considerably between breeds and genetically different forms of PRA can be broadly divided into early- and late-onset forms.

Early-onset forms of PRA Early onset forms of the disease are typically expressed between 2 and 6 weeks of age, the period of postnatal retinal differentiation in dogs, and are characterized by the abnormal development of the rod and cone photoreceptors. Four wellcharacterized, genetically distinct forms of autosomal recessive, early-onset retinal degeneration are rod-cone dysplasia type 1 (RCD1), rod-cone dysplasia type 2 (RCD2), rod-cone dysplasia type 3 (RCD3) and early retinal degeneration (ERD) [1]. RCD1, which affects Irish Setters from approximately 25 days after birth and culminates at about 1 year when the population of rods and cones is depleted, is caused by a nonsense mutation at codon 807 of the gene encoding the beta subunit of cGMP phosphodiesterase (PDE6B), an essential member of the phototransduction pathway [2]. This mutation was the first responsible for any form of PRA to be identified in the dog. An 8 base pair (bp) insertion after codon 816 in the same gene causes a genetically distinct form of PRA in the Sloughi which has a later age of onset than the Irish Setter form, with the first signs of visual impairment not being noticed until dogs are between 2 and 3 years of age [3]. PRA in the Cardigan Welsh corgi, termed rod-cone dysplasia 3 (RCD3), is also caused by a mutation in a subunit of cGMP phosphodiesterase, this time the alpha subunit, which results in a disease with a comparable age of onset to RCD1 [4]. In RCD3 affected dogs normal rod-mediated ERG responses fail to develop, photoreceptor outer segments do not reach maturity and rod cells are lost by apoptosis [5]. The genetically distinct RCD2 segregates in rough and smooth collies [6] and is caused by an insertion in $R D 3$ that results in a stretch of altered amino acids and an extended reading frame [7]. Mutations in RD3 have been associated with retinal degeneration in both humans and mice [8].

Whereas the early onset forms of PRA, RCD1 and RCD3, described above, were among the first canine inherited diseases to be characterized at the molecular level, the mutation responsible for the similarly early onset condition ERD (early-onset degeneration) has only recently been identified. This condition, which was originally described in Norwegian Elkhounds [9], and was first mapped more than 10 years ago [10] is caused by an exonic SINE insertion in the gene STK38L [11]. Although known to have neuronal cell functions STK38L has not previously been associated with abnormal photoreceptor function; being associated with such a disease in dogs establishes this gene as a potential candidate for similar diseases in other species, including man.

A different form of early-onset PRA affects Miniature Schnauzers. Histologically this disease is evident from a very early age, when the normal retina is nearing the end of postnatal differentiation, and as it affects both rods and cones it is termed photoreceptor dysplasia (PD) [12]. This disease was originally associated with a missense mutation in phosducin $(P D C)$ [13]. However additional research has since led to the complete exclusion of phosducin and to the identification of the gene and mutation that do in fact cause this disease, that is also known as Type A PRA [14]. Evidence suggests that Type A PRA is in fact a rare form of PRA in the Miniature Schnauzer and that other, genetically distinct forms of PRA segregate within the breed, for which the mutations have yet to be identified [14].

Recently a complex mutation, consisting of the combination of a one basepair deletion and a 6 basepair insertion was identified in exon 26 of CNGB1 in Papillons with an early onset PRA. The mutation leads to a frameshift and a premature stop codon. Affected dogs demonstrated an early lack of rod function followed by a slow retinal degeneration, a phenotype comparable to mice and humans with CNGB1 mutations [15]. CNGB1 combines with $C N G A 1$ to form the rod cyclic nucleotide gated channel. Previous studies have shown the requirement of CNGB1 for normal targeting of CNGA1 to the rod outer segment [16] and indeed the authors were able to demonstrate a lack of detectable CNGA1 protein in the rod outer segments of the affected Papillons homozygous for the mutation [15]. The same mutation was also described in Phalene dogs by Ahonen and collegues [17].

The early onset forms of PRA described above are all caused by mutations in autosomal genes. In contrast, a mutation in the X-linked retinitis pigmentosa GTPase regulator gene (RPGR) causes a very severe form of PRA, known as XLPRA2, that has been described in mixed breed dogs [18]. The XLPRA2 mutation is a 2 nucleotide deletion that results in a frameshift that significantly changes the predicted peptide sequence by leading to the replacement of many acidic glutamic acid residues with basic arginine residues and results in the premature termination of the protein 71 amino acids downstream. Unlike the genetically distinct, relatively late onset XLPRA1 that is described below, the phenotype associated with the frameshift mutation in XLPRA2 is very severe and manifests during retinal development. ERG abnormalities are evident by $5-6$ weeks of age and cell degeneration is present by 4 months, suggesting the mutant protein has a toxic gain of function that severely compromises the early stage of development of the photoreceptors. 
Late-onset forms of PRA The late-onset forms of PRA are degenerations of photoreceptors that have completed normal development. Whereas the genes implicated in early-onset diseases are those necessary for the correct development of photoreceptors the genes associated with later-onset forms of disease are those necessary for the long-term maintenance and function of these cells.

Progressive rod cone degeneration (PRCD) is a lateonset form of PRA that affects multiple breeds. Prior to characterization of this disease at the molecular level, elegant interbreed crosses were undertaken to determine that the phenotypically similar diseases that were segregating in multiple breeds, including the miniature poodle, the English and American cocker spaniels, the Labrador retriever, the Australian cattle dog, the Nova Scotia duck tolling retriever and the Portugese water dog, were in fact allelic $[19,20]$. However, when PRCD-affected dogs were mated to PRA-affected dogs of the Border Collie, Basenji and Italian greyhound breeds the progeny were normal, indicating these breeds are affected by genetically distinct forms of disease. The PRCD locus was mapped to a large region on CFA9 in 1998 [21] before the canine genome sequence was available and while tools with which to investigate the canine genome were relatively unsophisticated. However, the fact that a genetically identical disease segregated in so many breeds proved to be invaluable as it allowed the use of linkage disequilibrium mapping across affected breeds to considerably narrow the PRCDassociated region [22]. This led to the eventual identification of a single nucleotide substitution in the second codon of a previously unknown gene that is now known to be the cause of PRCD in at least 18 different breeds [23]. Intriguingly, an identical homozygous mutation was identified in a human patient with recessive retinitis pigmentosa, the human equivalent of PRA, and established the novel retinal gene, $P R C D$, as an important gene for the maintenance of rod photoreceptor structure and function across species.

A genetically distinct, late onset PRA has been described in the English Mastiff. This disease is unique, to date, among canine inherited retinopathies in that it is inherited as an autosomal dominant disease, and is caused by a single non-synonymous $\mathrm{C} \rightarrow \mathrm{G}$ transversion at nucleotide 11 of rhodopsin $(R H O)$ that changes Thr- 4 to Arg (T4R). Dogs carrying the RHO mutation have normal photoreceptor-specific ERG function at 3 to 6 months of age but by 13 months these responses are abnormal. In young affected dogs retinal structure, rhodopsin expression and photoreceptor activation is normal; disease progression is characterized by regions of initial focal photoreceptor degeneration surrounded by areas of structurally normal retina, which interestingly is very similar to the phenotypes of humans with $R H O$ mutations [24]. A characteristic component of the phenotype associated with T4R mutation is the dose-response relationship that has been demonstrated between light exposure and the early alterations in retinal tissue that occur in affected animals. Highest doses of light cause rapid loss of neurons, reaching complete degeneration of photoreceptors in $<4$ weeks whereas the lowest doses of light exposure enable mechanisms acting over a time scale of weeks to months to repair the abnormal alterations resulting from neuronal stress [25]. This mutation, originally identified in the English mastiff, has also been identified in PRA-affected bull mastiffs but has not been identified in any other breeds to date [26].

A different late onset form of autosomal recessive generalised PRA has been described in Schapendoes where the age of onset is typically between $2-5$ years. During the early stages of the disease affected dogs become night-blind, lacking the ability to adjust their vision to dim light; later their daytime vision also fails. This process of complete photoreceptor degeneration takes up to 2 years [27]. The causal mutation for the disease has been shown to be a single bp insertion in exon 6 of the recently discovered gene coiled-coil domain containing 66 (CCDC66) that leads to a stop codon. CCDC66 is evolutionarily conserved in different vertebrate species and exhibits a complex pattern of differential RNA splicing resulting in various isoforms in the retina. Immunohistochemically, CCDC66 protein is detected mainly in the inner segments of photoreceptors in mouse, dog, and man although the retinas of affected Schapendoes have been shown to lack CCDC66 protein [28].

A different mutation in RPGR from that associated with XLPRA2 (described above) is responsible for a sexlinked form of late-onset form PRA that was originally described in the Siberian Husky [29] known as XLPRA1. The mutation, which has also been identified in the Samoyed, is a five nucleotide deletion that causes a frameshift and an immediate premature stop; the truncated protein lacks $230 \mathrm{C}$-terminal amino acids which causes a slight decrease in the isoelectric point [18]. The photoreceptors of dogs that carry this mutation develop normally, in contrast to those of dogs with XLPRA2, and remain morphologically and functionally normal until young adulthood, indicating the C-terminal of the $R P G R$ protein is not essential for functional and structural differentiation of rods and cones.

Recently a frameshift mutation was identified in C2orf71 that causes an autosomal recessive form of late onset PRA in the Gordon and Irish Setters [30]. The average age of onset in the dogs studied was approximately 10 years of age. This variant was homozygous in 19 of 21 PRA cases and was at a frequency of approximately 0.37 in the Gordon Setter population. Approximately $10 \%$ of cases in this study ( 2 of 21) were not associated with the C2orf71 mutation, indicating that PRA in this breed is genetically 
heterogeneous and caused by at least two mutations. This variant is also present in a number of Irish Setter dogs with PRA and has an estimated allele frequency of 0.26 in the breed. The function of C2orf71 remains unknown, but it is important for retinal development and function and has previously been associated with autosomal recessive retinitis pigmentosa in humans [31-34]. The form of PRA associated with the mutation in $C 20 r f 71$ has been termed RCD4, for rod-cone degeneration 4, to distinguish it from other forms of rod-cone degeneration [30]. The mutation has also been found in Tibetan Terriers affected with PRA (Mellersh and Downs, unpublished).

All the progressive, late-onset retinal disorders described behave, more or less, as single-gene conditions, caused by highly penetrant mutations. There is, however, some evidence that environmental modifiers may play a role in some of these diseases, causing phenotypic variation between and within breeds [20].

\section{Cone-rod degenerations}

Cone-rod dystrophies are disorders predominantly of cones, with rods becoming affected later. CRDs have ophthalmoscopic changes that are very similar to those of PRA and detailed ERG studies that measure both cone and rod-specific responses are required to distinguish between the two types of condition. For this reason several disorders have been initially described as PRAs to be later re-classified when extensive ERG investigations have been undertaken.

One such disorder is a form of retinal degeneration that has been described in the Miniature longhaired dachshund (MLHD). The disease was originally described as an early-onset, autosomal recessive PRA with all affected dogs within an inbred research colony displaying ophthalmologic abnormalities that were detectable by ERG by six weeks of age and 25 weeks by fundoscopy and becoming blind by the time they were 2 years of age [35]. A subsequent electroretinography study identified an initial reduction of the cone photoreceptor function which led to the condition being reclassified as a cone-rod dystrophy (CRD), rather than a rod-led PRA, and the disease was termed CORD1 for cone-rod degeneration 1 [36]. The same condition has also been referred to as CRD4 by others, for cone-rod degeneration 4 [20]. Later findings by Lheriteau and coworkers were also consistent with the condition being a CRD [37]. Using the same colony of dogs CORD1 was mapped to a large region on CFA15 and a mutation in RPGRIP1 was identified that co-segregated completely with CORD1 in the research colony [38]. The mutation is a 44 bp insertion of a A29 tract flanked by a 15 bp duplication in exon 2 of the gene, that creates a frameshift and introduces a premature stop codon early in exon 3 . Mutations in RPGRIP1 have been associated with Leber congenital amaurosis (LCA) [39], retinitis pigmentosa (RP) [40] and CRD [41] in humans, as well as inherited retinal abnormalities in mice [42] which suggests it plays an important role in visual function. The gene product's precise role is not currently understood but it is thought to anchor regulatory complexes at the photoreceptor connecting cilium, which acts as a bridge between the inner and outer segments of photoreceptor cells [43] as well as having functions in disk morphogenesis [42] and in the structure of the ciliary axoneme [44]. RPGRIP1 also interacts with NPHP4, a gene that has been associated with a genetically distinct form of early-onset CRD segregating in the standard wire-haired variety of Dachshund [45-49]. Within the research colony of MLHDs there was complete correlation between the RPGRIP1 genotype and phenotype of the dogs with respect to their CORD1 phenotype whereas in the pet MLHD population this was not the case [50]. Outside of the colony there was considerable variation in the age of onset of retinal degeneration in dogs that were homozygous for the RPGRIP1 insertion (termed RPGRIP1-mutant), which has also been identified in other breeds, including the English springer spaniel (ESS) and the Beagle. In a study of a small number of RPGRIP1-mutant Beagles ERG cone responses were undetectable whereas rod responses were variable between dogs, and between eyes of the same dog [50]. In the same study all RPGRIP1-mutant MLHDs showed reduced cone responses, even in the absence of ophthalmoscopic abnormalities, a finding that has also been corroborated by Busse and co-workers [51]. Together these findings suggest that additional mutations are involved which modify the age of onset of ophthalmoscopic abnormalities associated with the RPGRIP1 mutation. Because the original research colony used was developed from a very small number of dogs it is a real possibility that the colony was fixed for these additional loci which, therefore, went undetected until the more outbred pet population was investigated. The mutation in NPHP4 described above, that causes an early onset cone-rod dystrophy in standard wire-haired dachshunds [49] was not present in the dachshunds studies by Miyadera, enabling that mutation to be excluded. A recent association study using RPGRIP1mutant MLHDs that had either early or late onset cord1 has indeed revealed a second locus that segregates with early-onset disease [52], indicating early onset CRD in MLHDs is more likely to be a digenic condition, and that the RPGRIP1 insertion alone causes a late onset CRD, although ERG abnormalities may be detected early in life.

Another form of canine cone-rod dystrophy to be characterized at the molecular level is crd3, for cone-rod dystrophy 3, that segregates in the Glen of Imaal terrier. This disease becomes evident ophthalmoscopically in affected dogs as young as 3 years of age, and progresses to end-stage retinal degeneration over several years. Very 
recently the causal mutation has been identified by two research groups almost simultaneously, as a large genomic deletion of ADAM9 (A Disintegrin And Metalloprotease domain, family member 9) that removes exons 15 and 16 of the ADAM9 transcript [53,54] and generates a premature stop codon that is predicted to result in a truncated protein that lacks critical domains. This finding established CRD3 as a true orthologue, and a potentially useful model, of the similar human condition CORD9 in which four distinct ADAM9 mutations have been found [55].

\section{Stationary retinal disorders}

The forms of both PRA and CRD described above are all inherited retinopathies that are characterized by increasing severity and decreasing visual function over time. Progressive retinal changes during the dog's lifetime invariably lead to complete blindness.

The first non-progressive retinopathy to be wellcharacterized was described in the Swedish Briard by Narfstrom and colleagues [56] as stationary and congenital, resulting in it being termed congenital stationary night blindness (CSNB). Since the initial report the disease has also been described as having a progressive component leading to it also being called a hereditary retinal dystrophy [57]. However CSNB and hereditary retinal dystrophy have since both been shown to be caused by a four nucleotide deletion in exon 5 of the RPE65 gene, indicating they are genetically identical conditions [58,59]. RPE65 is involved in the conversion of all-trans-retinoids to 11-cis-retinoids and in its absence the visual cycle is interrupted, resulting in a lack of visual pigment [60]. This canine disease has a very characteristic clinical phenotype; affected dogs have profound visual impairment present from at least 5-6 weeks of age, but remain ophthalmoscopically normal, at least for the first 3-4 years of life. Older dogs may show subtle retinal abnormalities indicative of a slowly progressive retinal degenerative process. Both cone and rod mediated ERG responses are highly abnormal, probably due to a combination of responses from rods and possibly cones with very reduced sensitivity [58]. It was the unique absence of visual function in dogs with healthy rod photoreceptors that was observed in CSNBaffected dogs that led to landmark studies in the field of retinal gene therapy. Subretinal injections of adenoassociated virus vectors expressing RPE65 resulted in restoration of rod photoreceptor function and improved visual function, first in dogs $[61,62]$ and subsequently in humans [63-65].

Cone degeneration (CD) is also different from other progressive disorders in that early-onset cone degeneration occurs in the absence of the subsequent rod degeneration that characterizes cone-rod dystrophies. In $c d$, which was originally described in Alaskan Malamutes
[66], affected puppies develop day-blindness and photophobia between 8 and 12 weeks of age, when retinal development is normally completed in dogs, although these clinical signs only occur in bright light and the dogs remain ophthalmoscopically normal throughout their entire lives. Cone function starts to deteriorate by the age of $6-12$ weeks and is unrecordable in adult dogs [67]. Rod photoreceptors, however, remain functionally and structurally normal throughout the animal's life. A large genomic deletion that removes all exons of $C N G B 3$, the gene that encodes the $\beta$ subunit of the cone cyclic nucleotide-gated cation channel, has been identified in CD-affected Alaskan Malamute-derived dogs, although there is evidence that the condition might be genetically heterogeneous in this breed as some dogs have been identified with clinical signs of day blindness that lack the CNGB3 deletion [68]. A missense mutation in the same gene has been detected in German Shorthaired Pointers affected with a clinically identical allelic disorder [69]. These findings established $C D$ as an orthologue of human achromatopsia, a condition also known as rod monochromacy or total congenital colour blindness, that shares many of its clinical features with $\mathrm{CD}$ and has also been associated with mutations in $C N G B 3$ [70,71]. The potential of these orthologues has recently been demonstrated by the successful restoration of cone function and associated photopic vision in both of the canine achromatopsia models by gene replacement therapy [72].

Another inherited retinal disorder that is generally nonprogressive is canine multifocal retinopathy $(C M R)$, a disease that has been recognized in several breeds, particularly Great Pyrenees, Coton de Tulear, English Mastiff and Bullmastiff $[73,74]$. Ophthalmoscopic changes are usually evident in affected dogs before the age of around 4 months and are characterized by multifocal areas of retinal elevation that contain subretinal accumulation of serous fluid. Retinal elevations can remain static for several years, whereas multifocal outer retinal atrophy is often seen in older animals. Several different variants in the Bestrophin gene (BEST1 (alias VMD2)) have been identified as likely causal mutations for $C M R$ in the dog. In Great Pyrenees, English Mastiff, and bullmastiff dogs, a C73T mutation in exon 2 causes a premature translation termination that limits the open-reading frame to 25 codons, compared with 580 codons in the wild-type mRNA (cmr1) and in Coton de Tulears a G482A transition changes an evolutionarily conserved glycine residue to aspartic acid (cmr2). In Lapponian Herders two coding changes have been described in CMR affected dogs; a deletion at nucleotide position 1,388 (c1388del) and a substitution at nucleotide position 1,466 . The c1388del results in a frame shift (Pro463fs) introducing a new stop codon at amino acid 490 and the G1466T substitution by itself leads to a conservative change in the amino acid sequence (Gly489Val), 
which is predicted to change the protein function with only marginal significance. In combination with the C1388del, however, the G1466T substitutions results in an additional stop codon at amino acid position 489 within the shifted reading frame (Gly489X). Since the mutations have only been found in complete linkage disequilibrium, the authors conclude that the combination of changes results in the disease they refer to as $c m r 3$ [75].

These mutations establish $C M R$ as a novel animal model for Best macular dystrophy (BMD) in humans, an autosomal dominant, childhood retinal disease also caused by mutations in the Bestrophin gene [76,77].

\section{Developmental diseases}

Retinal dysplasia is the term used to denote disorderly proliferation and imperfect differentiation of the developing retina and can be subdivided into focal, multifocal, geographic and total types. Focal and multifocal types manifest as linear folds and 'rosettes' of tissue in the inner (sensory) retinal layer whereas in geographic forms there are larger areas of defective retinal development that appear as large irregular or horseshoe-shaped areas of mixed hyper- or hyporeflectivity in the central retina. Total or generalized forms of retinal dysplasia have been described as an inherited trait in several breeds, including the Bedlington terrier [78], Sealyham terrier [79], Labrador retriever [80] and the Yorkshire terrier [81] and are associated with complete detachment of the abnormal neuroretina from the retinal pigment epithelium that results in blindness of affected eyes. All forms of retinal dysplasia are congenital and non-progressive. Retinal dysplasia appears to be inherited as an autosomal trait, at least in those breeds where sufficient numbers of individuals have been studied to reliably estimate the mode of inheritance [82-84]. The genetics of isolated or non-syndromic forms of retinal dysplasia have not been characterized at the molecular level in any breeds to date and no mutations have been associated with this condition.

Forms of syndromic retinal dysplasia have been reported in the Labrador retriever [85-87] and the Samoyed [88]. Homozygous affected dogs had short-limbed dwarfism and a range of ocular changes characterized by complete retinal detachment and cataract whereas heterozygous dogs had only focal or multifocal retinal lesions $[85,86]$. Breeding studies determined that these two disorders are non-allelic [89] and they were termed DRD1 (dwarfism with retinal dysplasia type 1 , Labrador retriever) and DRD2 (Samoyed), respectively (these conditions have also previously been referred to as OSD1 and OSD2 for oculoskeletal dysplasia). Mutations have recently been associated with both disorders; a 1-base pair insertional mutation in exon 1 of COL9A3 is associated with DRD1 and a 1,267-bp deletion in the 5' end of
COL9A2 co segregates with DRD2. Both mutations affect the COL3 domain of their respective genes, the expression of which are both reduced in affected retinas [90].

Another complex congenital defect of the retina is collie eye anomaly (CEA), although retinal involvement is secondary to the primary ocular defects associated with this disorder. The primary phenotypic element of the disorder is regional hypoplasia of the choroid, the highly vascular layer underlying the retina. Associated retinal lesions, known as colobomas are often detectable ophthalmoscopically, as are tortuous retinal vessels and multiple retinal folds in a minority of cases [91]. CEA, which segregates in several herding breeds with Collie ancestry, was mapped to a large region of CFA37 that included over 40 genes [92]; subsequently the fact that the disorder segregates in multiple, closely related breeds was used to reduce the size of the critical disease-associated region and pinpoint the causal mutation to a $7.8 \mathrm{~kb}$ intronic deletion in the NHEJ1 gene, which spans a highly conserved binding domain to which several developmentally important genes bind [91] The precise mechanism by which the deletion causes CEA has not however been established to date.

\section{Hereditary cataract}

The lens is the transparent, biconvex, avascular structure in the anterior segment of the eye that is partly responsible for the refraction of light to be focused on the retina. The lens consists of a nucleus, cortex and capsule and is suspended by many dense zonular ligaments which are attached to the capsule and connect between the ciliary body and the lens equator. Transparency is a crucial property of the lens which is achieved, in part, by the absence of light-scattering organelles within the lens fibres. New lens fibres are generated from the equatorial cells of the lens epithelium, which elongate, synthesize crystallin and finally lose their nuclei as they become mature lens fibres. The crystallins, which make up over $90 \%$ of the proteins in the lens, are specially adapted to contribute to the maintenance of transparency by forming soluble, high-molecular weight aggregates that need to stay in solution for the duration of an individual's life.

Cataracts are simply defined as opacities of the lens and can develop for a variety of reasons, including advanced age and the secondary effects of other diseases such as diabetes or progressive retinal atrophy, and trauma. Primary or hereditary cataracts $(\mathrm{HC})$ are common among dogs and are a leading cause of blindness. $\mathrm{HC}$ has been reported in as many as 97 different breeds $[93,94]$, with around 60 breeds being reported to be at increased risk compared to mixed-breed dogs [95]. Hereditary cataracts reported in different breeds vary with respect to their anatomic position within the lens, their age of onset and their progressive or stationary nature, 
although within a breed cataracts usually display marked breed specificity. Despite the large number of breeds affected by HC only a single gene, the transcription factor HSF4, has been implicated in the development of cataracts in dogs to date. HSF4 belongs to a family of heat shock transcription factors that regulate the expression of heat shock proteins in response to different stresses, such as oxidants, heavy metals, elevated temperatures and bacterial and viral infections [96]. Different mutations in HSF4 have been reported to cause both human autosomal dominant and recessive cataracts [97-99] and studies in mice have shown HSF4 is required for normal fibre cell differentiation during lens development $[100,101]$. Disruption of the gene leads to the development of cataracts via multiple pathways, including the down-regulation or loss of post-translational modification of different crystallin proteins [102]. A single recessive nucleotide insertion in exon 10 of the gene (CFA5 g.85286582_85286583insC), that causes a frameshift and introduces a premature stop codon, is responsible for an early onset, bilaterally symmetrical and progressive form of $\mathrm{HC}$ in the Staffordshire bull terrier [103]. This cataract starts to develop from a few months of age and invariably progresses to total cataract within 2-3 years if left untreated [104]. The mutation is shared by the Boston terrier, in which it causes the clinically identical early-onset hereditary cataract (EHC), one of two genetically distinct forms of cataract known to affect this breed $[104,105]$. The mutation associated with the clinically more variable, late-onset hereditary cataract (LHC) in this breed has yet to be identified [106]. The same mutation has also been identified in a small number of French bulldogs with a clinically identical cataract (Mellersh, unpublished).

A single nucleotide deletion at the same position in HSF4 (CFA5 g.85286582delC) has also been associated with $\mathrm{HC}$ in the Australian Shepherd. The form of cataract caused by the insertion identified in the Staffordshire bull terrier and related breeds has a recessive and highly penetrant mode of inheritance, is early onset, highly progressive and uniform. In contrast, the form of cataract observed in the Australian Shepherd, caused by the deletion described above, has a dominant, or co-dominant mode of inheritance, is not completely penetrant and is typically associated with a posterior polar subcapsular cataract that also has a variable age of onset. It is highly likely that other mutations associated with the development of cataracts are co-segregating in the Australian Shepherd population because not all the dogs with bilateral posterior polar subcapsular cataract carried a copy of the HSF4 deletion [107].

HSF4 has been excluded from involvement in the development of $\mathrm{HC}$ in a long list of breeds, including the Alaskan Malamute, American Cocker spaniel, Bichon Havanais, Belgian Shepherd Tervueren and Groenendael,
Dachshunds, English Cocker spaniels, English Miniature Terrier, Finnish Lapphund, Golden retriever, Griffon Bruxellois, Kromfohrlander, Jack Russell terrier, Lapponian Herder, Miniature Schnauzer, Miniature Pinscher, Nova Scotia Duck Tolling Retriever, Rottweiler, Samoyed, Schnauzer, and Tibetan Mastiff [103,107-111]. The paucity of canine cataract mutations that have been reported in the literature, compared to those associated with, for example, inherited retinal degenerations in the dog, is testament to the fact that $\mathrm{HC}$ is probably a genetically complex disorder in most breeds of dog and studies to date have not included the analysis of sufficient numbers of cases and controls to identify DNA variants associated with the disease. A recessive mode of inheritance has been suggested for congenital cataracts and microphthalmia in the Miniature Schnauzer [112] as well as cataracts in the Entlebucher mountain dog [113], the Bichon Frise [114] and the American Cocker spaniel [115]. In contrast, an autosomal dominant mode of inheritance with a high degree of penetrance has been suggested for the pulverulent (dust-like) form of cataract observed in the Norwegian Buhund [116] and autosomal dominant with variable penetrance has been suggested for inherited posterior polar subcapsular cataracts in the Labrador and Golden retriever [117], although current anecdotal evidence indicates that in the Labrador cataracts could also be inherited as an autosomal recessive trait. Evidence of inheritance has been reported for a handful of other breeds, including the Leonberger, Jack Russell terrier and Chow chow, although the precise mode of inheritance has rarely been identified [111,118,119].

\section{Primary lens luxation}

Primary lens luxation (PLL) is not a disease of the lens itself, but rather an inherited deterioration of the lens suspensory apparatus, the zonule, which is a system of fibres that suspend the lens from the ciliary body, maintaining it within the visual axis and in contact with the anterior surface of the vitreous body. In dogs affected with PLL ultrastructural abnormalities of the zonular fibers are already evident at 20 months of age [120] long before the lens luxation that typically occurs when the dogs are 3 to 8 years old, as a result of degeneration and breakdown of the zonules which cause the lens to be displaced from its normal position within the eye [121-124]. In the majority of cases the dislocated lens will pass into the anterior chamber where its presence is likely to cause acute glaucoma. The condition has been recognized as a canine familial disorder for more than 100 years $[125,126]$ and is encountered at high frequency in several terrier breeds and in some other breeds with probable terrier co-ancestry [121-124,127]. PLL is recessively inherited in the Tibetan terrier [127] and inheritance has been suggested to be recessive in 
the Shar Pei and other Western terrier breeds in which it has been studied [128]. A mutation in ADAMTS17 has been described as the cause of PLL in three breeds, the Miniature Bull terrier, the Lancashire Heeler and the Jack Russell terrier. The mutation is a $\mathrm{G} \rightarrow \mathrm{A}$ substitution at c. $1473+1$, which destroys a splice donor recognition site in intron 10 and causes exon skipping that results in a frameshift and the introduction of a premature termination codon [129]. The great majority of PLL-affected dogs are homozygous for the mutation, but a small minority are heterozygous, leading to speculation that carriers, of some breeds at least, might be at increased risk of developing the condition compared to dogs that are homozygous for the wildtype allele [129]. ADAMTS17 is one of 29 known mammalian members of the ADAMTS family of genes that encode secreted metalloproteases that proteolytically modify extracellular structural proteins. Mutations in a variety of ADAMTS genes have been associated with a diverse set of human diseases including Ehlers-Danlos syndrome [130] and WeillMarchesani syndrome [131]. The canine ADAMTS17 splice site mutation is shared by at least 17 different breeds, many of which are terriers or terrier-type breeds, but some of which have more diverse origins [132]. Some breeds that are known to be at increased risk of PLL, such as the Border Collie, do not carry the same ADAMTS17 mutation as the terrier breeds, indicating their form of the disease must be genetically distinct although clinically similar [132].

\section{Other conditions}

The diseases of the lens and retina described above represent the overwhelming majority of inherited eye conditions in the dog for which causal mutations have been identified. Many other ocular conditions have been reported to be more common in certain breeds than others, which is indicative that they have a genetic component. However, a rigorous estimate of the mode of inheritance has been undertaken for relatively few of these conditions. To list comprehensively all the eye conditions that have been reported in dogs is outside the scope of this review, so the remainder of conditions described is restricted to those conditions for which an estimate of the mode of inheritance or the heritability has been reported.

\section{Glaucoma}

Glaucoma is the term used to describe a group of conditions that result in increased intraocular pressure, with damage to the retinal ganglion cells and their axons, leading to vision loss and blindness. Glaucoma is commonly divided into congenital, primary and secondary types, depending on the aetiology of the condition. Congenital glaucoma is rare in the dog [133] and secondary glaucoma, which is the most common form of the condition observed in the dog, arises as result of antecedent or concurrent ocular disease, so is not itself inherited, although the primary, causal condition might be. Primary glaucoma occurs in the absence of any other ocular disease, and, therefore, is presumed to have a genetic component in most breeds. Primary glaucoma can occur in the presence (angle closure glaucoma) or absence (open angle glaucoma) of an abnormal, narrowed or closed opening into the ciliary cleft, which prevents the efficient drainage of aqueous humour from the anterior chamber of the eye, via the iridocorneal angle through openings between the pectinate fibres. Goniodysgenesis is the most common cause of primary glaucoma in dogs, and refers to the presence of abnormal, irregularly-shaped or imperforate sheets of pectinate fibres. Glaucoma has been reported to be more prevalent than average in several breeds, including the Flat Coated Retriever, American Cocker spaniel, the Bassett Hound, the Shar Pei, the Norwegian Elkhound and the Boston terrier [134-137]. A strong and significant correlation between goniodysgenesis and glaucoma was reported in the Great Dane, and the same study reported a high heritability for goniodysgenesis, suggesting glaucoma may be heritable in this breed [138]. A similarly significant association has been reported between pectinate ligament dysplasia and adult-onset primary glaucoma in the Flatcoated retriever, for which the heritability was estimated to be approximately $0.7[139,140]$. To date no mutations have been identified that are associated with angle closure glaucoma in any breed of dog although the first glaucomaassociated locus has recently been identified in Dandie Dinmont Terriers [141].

Autosomal recessive, primary open-angle glaucoma (POAG) has been very well characterized in the Beagle [142-146] and a Gly661Arg variant in ADAMTS10 has been associated with the condition in Beagles that developed elevated intraocular pressure from 8 to 16 months of age, due to increased resistance to outflow of aqueous humour despite normal appearing open iridocorneal angles [147].

\section{Persistent hyperplastic primary vitreous}

Persistent hyperplastic primary vitreous (PHPV) is a congenital, non-progressive condition which results from the abnormal regression of the foetal hyaloid vasculature. The condition is rare but is seen more commonly in Staffordshire bull terriers in which pedigree analysis supports a hereditary etiology for the condition but is insufficient to determine the exact mode of inheritance, $[148,149]$. PHPV and persistent hyperplastic tunica vasculosa lentis (PHTVL) has also been described in detail in the Doberman [150]. 


\section{Conclusion}

At the time of writing 29 different mutations have been associated with inherited eye disease in the domestic dog, and more are likely to have been identified by the time this review goes to press. This number far exceeds those associated with any other category of disease, meaning that inherited eye diseases are arguably better understood, at both the clinical and genetic level, than any other category of canine disease. The dog has already played an important role in emerging therapies for inherited blindness in humans and similarities in disease phenotype and eye structure and function between dog and man, together with the increasingly sophisticated genetic tools that are available for the dog, mean that the dog is likely to play an ever increasing role in both our understanding of the normal functioning of the eye and in our ability to treat inherited eye disorders.

\section{Competing interests}

The authors declare that they have no competing interests.

\section{Acknowledgements}

Funding from the Kennel Club Charitable Trust, PetPlan Charitable Trust, Morris Animal Foundation, Waltham Foundation and American Kennel Club Canine Health Foundation, is gratefully acknowledged, as well as support from numerous Breed Clubs and individuals. I would also like to thank all the owners and their dogs who have contributed to our studies over the years.

Received: 2 December 2013 Accepted: 6 March 2014

Published: 16 April 2014

\section{References}

1. Acland GM, Fletcher RT, Gentleman S, Chader GJ, Aguirre GD: Non-allelism of three genes ( $\mathrm{rcd} 1, \mathrm{rcd} 2$ and erd) for early-onset hereditary retinal degeneration. Exp Eye Res 1989, 49(6):983-998.

2. Suber ML, Pittler SJ, Qin N, Wright GC, Holcombe V, Lee RH, Craft CM, Lolley RN, Baehr W, Hurwitz RL: Irish setter dogs affected with rod/cone dysplasia contain a nonsense mutation in the rod CGMP phosphodiesterase beta-subunit gene. Proc Natl Acad Sci U S A 1993, 90(9):3968-3972.

3. Dekomien G, Runte M, Godde R, Epplen JT: Generalized progressive retinal atrophy of Sloughi dogs is due to an 8-bp insertion in exon 21 of the PDE6B gene. Cytogenet Cell Genet 2000, 90(3-4):261-267.

4. Petersen-Jones SM, Entz DD, Sargan DR: CGMP phosphodiesterase-alpha mutation causes progressive retinal atrophy in the Cardigan Welsh corgi dog. Invest Ophthalmol Vis Sci 1999, 40(8):1637-1644.

5. Tuntivanich N, Pittler SJ, Fischer AJ, Omar G, Kiupel M, Weber A, Yao S, Steibel JP, Khan NW, Petersen-Jones SM: Characterization of a canine model of autosomal recessive retinitis pigmentosa due to a PDE6A mutation. Invest Ophthalmol Vis Sci 2009, 50(2):801-813.

6. Wolf ED, Vainisi SJ, Santos-Anderson R: Rod-cone dysplasia in the collie. J Am Vet Med Assoc 1978, 173(10):1331-1333.

7. Kukekova AV, Goldstein O, Johnson JL, Richardson MA, Pearce-Kelling SE, Swaroop A, Friedman JS, Aguirre GD, Acland GM: Canine RD3 mutation establishes rod-cone dysplasia type $2(\operatorname{rcd} 2)$ as ortholog of human and murine rd3. Mamm Genome 2009, 20(2):109-123.

8. Friedman JS, Chang B, Kannabiran C, Chakarova C, Singh HP, Jalali S, Hawes NL, Branham K, Othman M, Filippova E, Thompson DA, Webster AR, Andreasson S, Jacobson SG, Bhattacharya SS, Heckenlively JR, Swaroop A: Premature truncation of a novel protein, RD3, exhibiting subnuclear localization is associated with retinal degeneration. Am J Hum Genet 2006, 79(6):1059-1070.

9. Acland GM, Aguirre GD: Retinal degenerations in the dog: IV. Early retinal degeneration (erd) in Norwegian elkhounds. Exp Eye Res 1987, 44(4):491-521.

10. Acland GM, Ray K, Mellersh CS, Gu W, Langston AA, Rine J, Ostrander EA, Aguirre GD: A novel retinal degeneration locus identified by linkage and comparative mapping of canine early retinal degeneration. Genomics 1999, 59:134-142.

11. Goldstein O, Kukekova AV, Aguirre GD, Acland GM: Exonic SINE insertion in STK38L causes canine early retinal degeneration (erd). Genomics 2010, 96(6):362-368

12. Parshall C, Wyman M, Nitroy A, Acland G, Aguirre G: Photoreceptor dysplasia: An inherited progressive retinal atrophy in miniature schnauzer dogs. Prog Vet Comp Ophthalmol 1991, 1:187-203.

13. Zhang Q, Acland GM, Parshall CJ, Haskell J, Ray K, Aguirre GD: Characterization of canine photoreceptor phosducin CDNA and identification of a sequence variant in dogs with photoreceptor dysplasia. Gene 1998, 215(2):231-239.

14. Type A-PRA Test. http://www.optigen.com/opt9_test_a_pra.html.

15. Winkler PA, Ekenstedt KJ, Occelli LM, Frattaroli AV, Bartoe JT, Venta PJ, Petersen-Jones SM: A large animal model for CNGB1 autosomal recessive retinitis pigmentosa. PLOS ONE 2013, 8(8):e72229.

16. Zhang Y, Molday LL, Molday RS, Sarfare SS, Woodruff ML, Fain GL, Kraft TW, Pittler SJ: Knockout of GARPs and the beta-subunit of the rod CGMP-gated channel disrupts disk morphogenesis and rod outer segment structural integrity. J Cell Sci 2009, 122(Pt 8):1192-200.

17. Ahonen SJ, Arumilli M, Lohi H: A CNGB1 frameshift mutation in papillon and phalene dogs with progressive retinal atrophy. PLOS ONE 2013, 8(8):e72122.

18. Zhang Q, Acland GM, Wu WX, Johnson JL, Pearce-Kelling S, Tulloch B, Vervoort R, Wright AF, Aguirre GD: Different RPGR exon ORF15 mutations in Canids provide insights into photoreceptor cell degeneration. Hum Mol Genet 2002, 11(9):993-1003.

19. Aguirre GD, Acland GM: Variation in retinal degeneration phenotype inherited at the prod locus. Exp Eye Res 1988, 46(5):663-687.

20. Aguirre GD, Acland GM: Models, mutants and man; searching for unique phenotypes and genes in the dog model of inherited retinal degeneration. In The dog and its genome. Edited by Ostrander EA, Giger G, Lindblad-Toh K. New York: Cold Spring Harbour Laboratory Press; 2006:291-325.

21. Acland GM, Ray K, Mellersh CS, Gu W, Langston AA, Rine J, Ostrander EA, Aguirre GD: Linkage analysis and comparative mapping of canine progressive rod-cone degeneration (prcd) establishes potential locus homology with retinitis pigmentosa (RP17) in humans. Proc Natl Acad Sci U S A 1998, 96(6):3048-3053.

22. Goldstein O, Zangerl B, Pearce-Kelling S, Sidjanin DJ, Kijas JW, Felix J, Acland GM, Aguirre GD: Linkage disequilibrium mapping in domestic dog breeds narrows the progressive rod-cone degeneration interval and identifies ancestral disease-transmitting chromosome. Genomics 2006, 88(5):541-50.

23. Zangerl B, Goldstein O, Philp AR, Lindauer SJ, Pearce-Kelling SE, Mullins RF, Graphodatsky AS, Ripoll D, Felix JS, Stone EM, Acland GM, Aguirre GD: Identical mutation in a novel retinal gene causes progressive rod-cone degeneration in dogs and retinitis pigmentosa in humans. Genomics 2006, 88(5):551-63.

24. Kijas JW, Cideciyan AV, Aleman TS, Pianta MJ, Pearce-Kelling SE, Miller BJ, Jacobson SG, Aguirre GD, Acland GM: Naturally occurring rhodopsin mutation in the dog causes retinal dysfunction and degeneration mimicking human dominant retinitis pigmentosa. Proc Natl Acad SCi U S A 2002, 99(9):6328-33.

25. Cideciyan AV, Jacobson SG, Aleman TS, Gu D, Pearce-Kelling SE, Sumaroka A, Acland GM, Aguirre GD: In vivo dynamics of retinal injury and repair in the rhodopsin mutant dog model of human retinitis pigmentosa. Proc Natl Acad Sci U S A 2005, 102(14):5233-8.

26. Kijas JW, Miller BJ, Pearce-Kelling SE, Aguirre GD, Acland GM: Canine models of ocular disease: outcross breedings define a dominant disorder present in the english mastiff and bull mastiff dog breeds. $J$ Hered 2003, 94(1):27-30.

27. Lippmann T, Jonkisz A, Dobosz T, Petrasch-Parwez E, Epplen JT, Dekomien G: Haplotype-defined linkage region for gPRA in Schapendoes dogs. Mol Vis 2007, 13:174-80.

28. Dekomien G, Vollrath C, Petrasch-Parwez E, Boeve MH, Akkad DA, Gerding WM, Epplen JT: Progressive retinal atrophy in Schapendoes dogs: mutation of the newly identified CCDC66 gene. Neurogenetics. 2010, 11(2):163-174.

29. Acland GM, Blanton SH, Hershfield B, Aguire GD: XLPRA: a canine retinal degeneration inherited as an X-linked trait. Am J Med Genet 1994, 52:27-33. 
30. Downs LM, Bell JS, Freeman J, Hartley C, Hayward LJ, Mellersh CS: Lateonset progressive retinal atrophy in the Gordon and Irish Setter breeds is associated with a frameshift mutation in C2orf71. Anim Genet 2013, 44(2):169-77.

31. Audo I, Lancelot ME, Mohand-Said S, Antonio A, Germain A, Sahel JA, Bhattacharya SS, Zeitz C: Novel C2orf71 mutations account for approximately $1 \%$ of cases in a large French arRP cohort. Hum Mutat 2011, 32(4):E2091-103.

32. Sergouniotis PI, Li Z, Mackay DS, Wright GA, Borman AD, Devery SR, Moore AT, Webster AR: A survey of DNA variation of C2ORF71 in probands with progressive autosomal recessive retinal degeneration and controls. Invest Ophthalmol Vis Sci 2011, 52(3):1880-6.

33. Nishimura DY, Baye LM, Perveen R, Searby CC, Avila-Fernandez A, Pereiro I, Ayuso C, Valverde D, Bishop PN, Manson FD, Urquhart J, Stone EM, Slusarski DC, Black GC, Sheffield VC: Discovery and functional analysis of a retinitis pigmentosa gene, C2ORF71. Am J Hum Genet 2010, 86(5):686-95.

34. Collin RW, Safieh C, Littink KW, Shalev SA, Garzozi HJ, Rizel L, Abbasi AH, Cremers FP, den Hollander Al, Klevering BJ, Ben-Yosef T: Mutations in C2ORF71 cause autosomal-recessive retinitis pigmentosa. Am J Hum Genet 2010, 86(5):783-8.

35. Curtis R, Barnett KC: Progressive retinal atrophy in miniature longhaired dachshund dogs. Br Vet J 1993, 149(1):71-85.

36. Turney $\mathrm{C}$, Chong NH, Alexander RA, Hogg CR, Fleming L, Flack D, Barnett KC, Bird AC, Holder GE, Luthert PJ: Pathological and electrophysiological features of a canine cone-rod dystrophy in the miniature longhaired dachshund. Invest Ophthalmol Vis Sci 2007, 48(9):4240-9.

37. Lheriteau E, Libeau L, Stieger K, Deschamps JY, Mendes-Madeira A, Provost N, Lemoine F, Mellersh C, Ellinwood NM, Cherel Y, Moullier P, Rolling F: The RPGRIP1-deficient dog, a promising canine model for gene therapy. Mol Vis 2009, 15:349-61.

38. Mellersh CS, Boursnell ME, Pettitt L, Ryder EJ, Holmes NG, Grafham D, Forman OP, Sampson J, Barnett KC, Blanton S, Binns MM, Vaudin M: Canine RPGRIP1 mutation establishes cone-rod dystrophy in miniature longhaired dachshunds as a homologue of human Leber congenital amaurosis. Genomics 2006, 88(3):293-301.

39. Dryja TP, Adams SM, Grimsby JL, McGee TL, Hong DH, Li T, Andreasson S, Berson EL: Null RPGRIP1 alleles in patients with Leber congenital amaurosis. Am J Hum Genet 2001, 68(5):1295-8.

40. Booij JC, Florijn RJ, ten Brink JB, Loves W, Meire F, van Schooneveld MJ, de Jong PT, Bergen AA: Identification of mutations in the AIPL1, CRB1, GUCY2D, RPE65, and RPGRIP1 genes in patients with juvenile retinitis pigmentosa. Journal of Medical Genetics 2005, 42(11):e67.

41. Hameed A, Abid A, Aziz A, Ismail M, Mehdi SQ, Khaliq S: Evidence of RPGRIP1 gene mutations associated with recessive cone-rod dystrophy. J Med Genet 2003, 40(8):616-9.

42. Zhao Y, Hong DH, Pawlyk B, Yue G, Adamian M, Grynberg M, Godzik A, Li T: The retinitis pigmentosa GTPase regulator (RPGR)- interacting protein subserving RPGR function and participating in disk morphogenesis. Proc Natl Acad Sci U S A 2003, 100(7):3965-70.

43. Roepman R, Bernoud-Hubac N, Schick DE, Maugeri A, Berger W, Ropers HH, Cremers FP, Ferreira PA: The retinitis pigmentosa GTPase regulator (RPGR) interacts with novel transport-like proteins in the outer segments of rod photoreceptors. Hum Mol Genet 2000, 9(14):2095-105.

44. Hong DH, Yue G, Adamian M, Li T: Retinitis pigmentosa GTPase regulator (RPGRr)-interacting protein is stably associated with the photoreceptor ciliary axoneme and anchors RPGR to the connecting cilium. J Biol Chem 2001, 276(15):12091-9.

45. Ropstad EO, Bjerkas E, Narfstrom K: Clinical findings in early onset cone-rod dystrophy in the Standard Wire-haired Dachshund. Vet Ophthalmol 2007, 10(2):69-75.

46. Ropstad EO, Bjerkas E, Narfstrom K: Electroretinographic findings in the Standard Wire Haired Dachshund with inherited early onset cone-rod dystrophy. Doc Ophthalmol 2007, 114(1):27-36.

47. Wiik AC, Ropstad EO, Bjerkas E, Lingaas F: A study of candidate genes for day blindness in the standard wire haired dachshund. BMC Vet Res 2008 4:23.

48. Wiik AC, Thoresen SI, Wade C, Lindblad-Toh K, Lingaas F: A population study of a mutation allele associated with cone-rod dystrophy in the standard wire-haired dachshund. Anim Genet 2009, 40(4):572-4.

49. Wiik AC, Wade C, Biagi T, Ropstad EO, Bjerkas E, Lindblad-Toh K, Lingaas F: A deletion in nephronophthisis 4 (NPHP4) is associated with recessive cone-rod dystrophy in standard wire-haired dachshund. Genome Res 2008, 18(9):1415-21.

50. Miyadera K, Kato K, Aguirre-Hernandez J, Tokuriki T, Morimoto K, Busse C, Barnett K, Holmes N, Ogawa H, Sasaki N, Mellersh CS, Sargan DR: Phenotypic variation and genotype-phenotype discordance in canine cone-rod dystrophy with an RPGRIP1 mutation. Mol Vis 2009, 15:2287-305.

51. Busse C, Barnett KC, Mellersh CS, Adams VJ: Ophthalmic and cone derived electrodiagnostic findings in outbred Miniature Long-haired Dachshunds homozygous for a RPGRIP1 mutation. Vet Ophthalmol 2011, 14(3):146-52.

52. Miyadera K, Kato K, Boursnell M, Mellersh CS, Sargan DR: Genome-wide association study in RPGRIP1 (-/-) dogs identifies a modifier locus that determines the onset of retinal degeneration. Mamm Genome 2012, 23(1-2):212-23.

53. Goldstein O, Mezey JG, Boyko AR, Gao C, Wang W, Bustamante CD, Anguish LJ, Jordan JA, Pearce-Kelling SE, Aguirre GD, Acland GM: An ADAM9 mutation in canine cone-rod dystrophy 3 establishes homology with human cone-rod dystrophy 9. Mol Vis 2010, 16:1549-69.

54. Kropatsch R, Petrasch-Parwez E, Seelow D, Schlichting A, Gerding WM, Akkad DA, Epplen JT, Dekomien G: Generalized progressive retinal atrophy in the Irish Glen of Imaal Terrier is associated with a deletion in the ADAM9 gene. Mol Cell Probes 2010, 24(6):357-63.

55. Parry DA, Toomes C, Bida L, Danciger M, Towns KV, McKibbin M, Jacobson SG, Logan CV, Ali M, Bond J, Chance R, Swendeman S, Daniele LL, Springell K, Adams M, Johnson CA, Booth AP, Jafri H, Rashid Y, Banin E, Strom TM, Farber DB, Sharon D, Blobel CP, Pugh EN Jr, Pierce EA, Inglehearn CF: Loss of the metalloprotease ADAM9 leads to cone-rod dystrophy in humans and retinal degeneration in mice. Am J Hum Genet 2009, 84(5):683-91.

56. Narfstrom K, Wrigstad A, Nilsson SE: The Briard dog: a new animal model of congenital stationary night blindness. Br J Ophthalmol 1989, 73(9):750-6

57. Wrigstad A, Narfstrom K, Nilsson SE: Slowly progressive changes of the retina and retinal pigment epithelium in Briard dogs with hereditary retinal dystrophy. A morphological study. Doc Ophthalmol 1994, 87(4):337-54.

58. Aguirre GD, Baldwin V, Pearce-Kelling S, Narfstrom K, Ray K, Acland GM: Congenital stationary night blindness in the dog: common mutation in the RPE65 gene indicates founder effect. Mo/ Vis 1998, 4:23.

59. Veske A, Nilsson SE, Narfstrom K, Gal A: Retinal dystrophy of Swedish briard/briard-beagle dogs is due to a 4-bp deletion in RPE65. Genomics 1999, 57(1):57-61.

60. Bok D: The role of RPE65 in inherited retinal diseases. Retina 2005, 25(8 Suppl):S61-S62

61. Acland GM, Aguirre GD, Ray J, Zhang Q, Aleman TS, Cideciyan AV, Pearce-Kelling SE, Anand V, Zeng Y, Maguire AM, Jacobson SG, Hauswirth WW, Bennett J: Gene therapy restores vision in a canine model of childhood blindness. Nat Genet 2001, 28(1):92-5.

62. Le Meur G, Stieger K, Smith AJ, Weber M, Deschamps JY, Nivard D, Mendes-Madeira A, Provost N, Pereon Y, Cherel Y, Ali RR, Hamel C, Moullier $P$, Rolling F: Restoration of vision in RPE65-deficient Briard dogs using an AAV serotype 4 vector that specifically targets the retinal pigmented epithelium. Gene Ther 2007, 14(4):292-303.

63. Bainbridge JW, Smith AJ, Barker SS, Robbie S, Henderson R, Balaggan K, Viswanathan A, Holder GE, Stockman A, Tyler N, Petersen-Jones S, Bhattacharya SS, Thrasher AJ, Fitzke FW, Carter BJ, Rubin GS, Moore AT, Ali RR: Effect of gene therapy on visual function in Leber's congenital amaurosis. N Engl J Med 2008, 358(21):2231-9.

64. Hauswirth WW, Aleman TS, Kaushal S, Cideciyan AV, Schwartz SB, Wang L, Conlon TJ, Boye SL, Flotte TR, Byrne BJ, Jacobson SG: Treatment of leber congenital amaurosis due to RPE65 mutations by ocular subretinal injection of adeno-associated virus gene vector: short-term results of a phase I trial. Hum Gene Ther 2008, 19(10):979-90.

65. Maguire AM, Simonelli F, Pierce EA, Pugh EN Jr, Mingozzi F, Bennicelli J, Banfi S, Marshall KA, Testa F, Surace EM, Rossi S, Lyubarsky A, Arruda VR, Konkle B, Stone E, Sun J, Jacobs J, Dell'Osso L, Hertle R, Ma JX, Redmond TM, Zhu X, Hauck B, Zelenaia O, Shindler KS, Maguire MG, Wright JF, Volpe NJ, McDonnell JW, Auricchio A, et al: Safety and efficacy of gene transfer for Leber's congenital amaurosis. N Engl J Med 2008, 358(21):2240-8.

66. Rubin LF, Bourns TK, Lord LH: Hemeralopia in dogs: heredity of hemeralopia in Alaskan Malamutes. American Journal of Veterinary Research 1967, 28(123):355-7. 
67. Aguirre GD, Rubin LF: The electroretinogram in dogs with inherited cone degeneration. Investig Ophthalmol 1975, 14(11):840-7.

68. Seddon JM, Hampson EC, Smith RI, Hughes IP: Genetic heterogeneity of day blindness in Alaskan Malamutes. Anim Genet 2006, 37(4):407-10.

69. Sidjanin DJ, Lowe JK, McElwee JL, Milne BS, Phippen TM, Sargan DR, Aguirre GD, Acland GM, Ostrander EA: Canine CNGB3 mutations establish cone degeneration as orthologous to the human achromatopsia locus ACHM3. Hum Mol Genet 2002, 11(16):1823-33.

70. Kohl S, Baumann B, Broghammer M, Jagle H, Sieving P, Kellner U, Spegal R, Anastasi M, Zrenner E, Sharpe LT, Wissinger B: Mutations in the CNGB3 gene encoding the beta-subunit of the cone photoreceptor cGMP-gated channel are responsible for achromatopsia (ACHM3) linked to chromosome 8q21. Hum Mol Genet 2000, 9(14):2107-16.

71. Sundin OH, Yang JM, Li Y, Zhu D, Hurd JN, Mitchell TN, Silva ED, Maumenee $\mathrm{IH}$ : Genetic basis of total colourblindness among the Pingelapese islanders. Nat Genet 2000, 25(3):289-293.

72. Komaromy AM, Alexander JJ, Rowlan JS, Garcia MM, Chiodo VA, Kaya A, Tanaka JC, Acland GM, Hauswirth WW, Aguirre GD: Gene therapy rescues cone function in congenital achromatopsia. Hum Mol Genet 2010, 19(13):2581-93,

73. Grahn BH, Philibert H, Cullen CL, Houston DM, Semple HA, Schmutz SM: Multifocal retinopathy of Great Pyrenees dogs. Vet Ophthalmol 1998, 1(4):211-221.

74. Guziewicz KE, Zangerl B, Lindauer SJ, Mullins RF, Sandmeyer LS, Grahn BH, Stone EM, Acland GM, Aguirre GD: Bestrophin gene mutations cause canine multifocal retinopathy: a novel animal model for best disease. Invest Ophthalmol Vis Sci 2007, 48(5):1959-67.

75. Zangerl B, Wickstrom K, Slavik J, Lindauer SJ, Ahonen S, Schelling C, Lohi H, Guziewicz KE, Aguirre GD: Assessment of canine BEST1 variations identifies new mutations and establishes an independent bestrophinopathy model (cmr3). Mol Vis 2010, 16:2791-804.

76. Lorenz B, Preising MN: Best's disease. Overview of pathology and its causes. Ophthalmologe 2005, 102(2):111-5.

77. Xiao Q, Hartzell HC, Yu K: Bestrophins and retinopathies. Pflugers Archiv. Eur J Physiol 2010, 460(2):559-69.

78. Rubin LF: Hereditary retinal dysplasia in Bedlington terriers. J Am Veterinary Med Assoc 1968, 19:260-262.

79. Ashton N, Barnett KC, Sachs DD: Retinal dysplasia in the Sealyham terrier. J Pathology Bacterio/ 1968, 96(2):269-72.

80. Barnett KC, Bjorck GR, Kock E: Hereditary retinal dysplasia in the labrador retriever in England and Sweden. J Animal Pract 1970, 10:755-759.

81. Stades FC: Hereditary retinal dysplasia (RD) in a family of Yorkshire terriers. Tijdschr Diergeneeskd 1978, 103(20):1087-90.

82. Crispin SM, Long SE, Wheeler CA: Incidence and ocular manifestations of multifocal retinal dysplasia in the golden retriever in the uk. Vet Rec 1999, 145:669-72

83. Long SE, Crispin SM: Inheritance of multifocal retinal dysplasia in the golden retriever in the UK. Vet Rec 1999, 145(24):702-4.

84. MacMillan AD, Lipton DE: Heritability of multifocal retinal dysplasia in American Cocker Spaniels. J Am Veterinary Med Assoc 1978, 172(5):568-72.

85. Carrig CB, MacMillan A, Brundage S, Pool RR, Morgan JP: Retinal dysplasia associated with skeletal abnormalities in Labrador Retrievers. J Am Veterinary Med Assoc 1977, 170(1):49-57.

86. Carrig CB, Sponenberg DP, Schmidt GM, Tvedten HW: Inheritance of associated ocular and skeletal dysplasia in Labrador retrievers. J Am Veterinary Med Assoc 1988, 193(10):1269-72.

87. Nelson DL, Macmillan AD: Multifocal retinal dysplasia in field trial labrador retrievers. J Am Animal Hospital Assoc 1983, 19:388-392.

88. Meyers VN, Jezyk PF, Aguirre GD, Patterson DF: Short-limbed dwarfism and ocular defects in the Samoyed dog. J Am Veterinary Med Assoc 1983, 183(9):975-9.

89. Acland GM, Aguirre GD: Oculoskeletal dysplasia in samoyed and Labrador retriever dogs: 2 nonallelic disorders akin to Stickler-like syndromes affecting humans. In 2nd International DOGMAP meeting. Cambridge, UK: 1995.

90. Goldstein O, Guyon R, Kukekova A, Kuznetsova TN, Pearce-Kelling SE, Johnson J, Aguirre GD, Acland GM: COL9A2 and COL9A3 mutations in canine autosomal recessive oculoskeletal dysplasia. Mamm Genome 2010, 21(7-8):398-408.

91. Parker HG, Kukekova AV, Akey DT, Goldstein O, Kirkness EF, Baysac KC, Mosher DS, Aguirre GD, Acland GM, Ostrander EA: Breed relationships facilitate fine-mapping studies: a 7.8-kb deletion cosegregates with Collie eye anomaly across multiple dog breeds. Genome Res 2007, 17(11):1562-71.

92. Lowe JK, Kukekova AV, Kirkness EF, Langlois MC, Aguirre GD, Acland GM, Ostrander EA: Linkage mapping of the primary disease locus for collie eye anomaly. Genomics 2003, 82(1):86-95.

93. Davidson MG, Nelms SR: Diseases of the canine lens and cataract formation. In In Veterinary Ophthalmology. Edited by Gelatt K. 9600 Garsington Road, Oxford, OX4 2DQ, UK: Blackwell Publishing Ltd; 2007:859-887.

94. Rubin LF: Inherited Eye Diseases in Purebred Dogs. Baltimore: Williams \& Wilkins; 1989:363.

95. Gelatt KN, Mackay EO: Prevalence of primary breed-related cataracts in the dog in North America. Vet Ophthalmol 2005, 8(2):101-11.

96. Nakai A, Tanabe M, Kawazoe Y, Inazawa J, Morimoto Rl, Nagata K: HSF4, a new member of the human heat shock factor family which lacks properties of a transcriptional activator. Mol Cell Biol 1997, 17(1):469-81.

97. Bu L, Jin $Y$, Shi $Y$, Chu R, Ban A, Eiberg $H$, Andres $L$, Jiang $H$, Zheng G, Qian M, Cui B, Xia Y, Liu J, Hu L, Zhao G, Hayden MR, Kong X: Mutant DNAbinding domain of HSF4 is associated with autosomal dominant lamellar and Marner cataract. Nat Genet 2002, 31(3):276-8.

98. Forshew T, Johnson CA, Khaliq S, Pasha S, Willis C, Abbasi R, Tee L, Smith U, Trembath RC, Mehdi SQ, Moore AT, Maher ER: Locus heterogeneity in autosomal recessive congenital cataracts: linkage to $9 q$ and germline HSF4 mutations. Human Genetics 2005, 117(5):452-9.

99. Smaoui N, Beltaief O, BenHamed S, M'Rad R, Maazoul F, Ouertani A, Chaabouni $\mathrm{H}$, Hejtmancik JF: A homozygous splice mutation in the HSF4 gene is associated with an autosomal recessive congenital cataract. Investigative Ophthalmol Vis Sci 2004, 45(8):2716-21.

100. Fujimoto M, Izu H, Seki K, Fukuda K, Nishida T, Yamada S, Kato K, Yonemura $S$, Inouye S, Nakai A: HSF4 is required for normal cell growth and differentiation during mouse lens development. EMBO J 2004, 23 (21):4297-306.

101. Min JN, Zhang Y, Moskophidis D, Mivechi NF: Unique contribution of heat shock transcription factor 4 in ocular lens development and fiber cell differentiation. Genesis 2004, 40(4):205-17.

102. Shi X, Cui B, Wang Z, Weng L, Xu Z, Ma J, Xu G, Kong X, Hu L: Removal of Hsf4 leads to cataract development in mice through down-regulation of gamma S-crystallin and Bfsp expression. BMC Mol Biol 2009, 10:10.

103. Mellersh CS, Pettitt L, Forman OP, Vaudin M, Barnett KC: Identification of mutations in HSF4 in dogs of three different breeds with hereditary cataracts. Veterinary Ophthalmol 2006, 9(5):369-78.

104. Barnett KC: Hereditary cataract in the dog. J Small Animal Pract 1978, 19(2):109-20.

105. Curtis R: Late-onset cataract in the Boston terrier. Vet Rec 1984 , 115(22):577-8

106. Mellersh CS, Graves KT, McLaughlin B, Ennis RB, Pettitt L, Vaudin M, Barnett KC: Mutation in HSF4 Associated with Early but Not Late-Onset Hereditary Cataract in the Boston Terrier. J Hered 2007, 98(5):531-3.

107. Mellersh CS, McLaughlin B, Ahonen S, Pettitt L, Lohi H, Barnett KC: Mutation in HSF4 is associated with hereditary cataract in the Australian Shepherd. Vet Ophthalmol 2009, 12(6):372-8.

108. Muller C, Distl O: Scanning 17 candidate genes for association with primary cataracts in the wire-haired Dachshund. Veterinary J 2009, 182(2):342-5.

109. Muller C, Wohlke A, Distl O: Evaluation of canine heat shock transcription factor 4 (HSF4) as a candidate gene for primary cataracts in the Dachshund and the Entlebucher Mountain dog. Veterinary Ophthalmol 2008, 11(1):34-7.

110. Engelhardt A, Wohlke A, Distl O: Evaluation of canine heat-shock transcription factor 4 as a candidate for primary cataracts in English Cocker Spaniels and wire-haired Kromfohrlanders. J Anim Breed Genet 2007, 124(4):242-5.

111. Oberbauer AM, Hollingsworth SR, Belanger JM, Regan KR, Famula TR: Inheritance of cataracts and primary lens luxation in Jack Russell Terriers. Am J Veterinary Res 2008, 69(2):222-7.

112. Gelatt KN, Samuelson DA, Bauer JE, Das ND, Wolf ED, Barrie KP, Andresen $\mathrm{TL}$ : Inheritance of congenital cataracts and microphthalmia in the Miniature Schnauzer. Am J Veterinary Res 1983, 44(6):1130-2.

113. Spiess BM: Inherited eye diseases in the Entlebucher mountain dog. Schweiz Arch Tierheilkd 1994, 136(3):105-10. 
114. Wallace MR, MacKay EO, Gelatt KN, Andrew SE: Inheritance of cataract in the Bichon Frise. Veterinary Ophthalmol 2005, 8(3):203-5.

115. Yakely WL: A study of heritability of cataracts in the American Cocker Spaniel. JAVMA 1978, 172(7):814-817.

116. Bjerkas E, Haaland MB: Pulverulent nuclear cataract in the Norwegian buhund. J Small Animal Pract 1995, 36(11):471-4.

117. Curtis R, Barnett KC: A survey of cataracts in the golden and labrador retrievers. J Small Animal Pract 1989, 30:277-286.

118. Collins BK, Collier LL, Johnson GS, Shibuya H, Moore CP, da Silva Curiel JM: Familial cataracts and concurrent ocular anomalies in chow chows. J Am Veterinary Med Assoc 1992, 200(10):1485-91.

119. Heinrich $\mathrm{CL}$, Lakhani $\mathrm{KH}$, Featherstone $\mathrm{HJ}$, Barnett $\mathrm{KC}$ : Cataract in the UK Leonberger population. Veterinary Ophthalmol 2006, 9(5):350-6.

120. Curtis R: Aetiopathological aspects of inherited lens dislocation in the Tibetan Terrier. J Comparative Pathol 1983, 93(1):151-63.

121. Curtis R: Lens luxation in the dog and cat. Vet Clin North Am Small Anim Pract 1990, 20(3):755-73.

122. Curtis R, Barnett KC: Primary lens luxation in the dog. J Small Anim Pract 1980, 21(12):657-68

123. Curtis R, Barnett KC, Lewis SJ: Clinical and pathological observations concerning the aetiology of primary lens luxation in the dog. Vet Rec 1983, 112(11):238-46.

124. Morris RA, Dubielzig RR: Light-microscopy evaluation of zonular fiber morphology in dogs with glaucoma: secondary to lens displacement. Veterinary Ophthalmol 2005, 8(2):81-4.

125. Gray H: The diseases of the eye in domesticated animnals. Vet. Rec. 1909 , 21:678.

126. Gray H: Some medical and surgical conditions in the dog and cat. Vet Rec 1932, 12:1-10.

127. Willis MB, Curtis R, Barnett KC, Tempest WM: Genetic aspects of lens luxation in the Tibetan terrier. Vet Rec 1979, 104(18):409-12.

128. Sargan DR, Withers D, Pettitt L, Squire M, Gould DJ, Mellersh CS: Mapping the mutation causing lens luxation in several terrier breeds. J Hered 2007 98(5):534-8

129. Farias FH, Johnson GS, Taylor JF, Giuliano E, Katz ML, Sanders DN, Schnabe RD, McKay SD, Khan S, Gharahkhani P, O'Leary CA, Pettitt L, Forman OP, Boursnell M, McLaughlin B, Ahonen S, Lohi H, Hernandez-Merino E, Gould DJ, Sargan D, Mellersh CS: An ADAMTS17 Splice Donor Site Mutation in Dogs with Primary Lens Luxation. Investigative Ophthalmol Visual Sci 2010 $51: 4716-4721$

130. Colige A, Sieron AL, Li SW, Schwarze U, Petty E, Wertelecki W, Wilcox W, Krakow D, Cohn DH, Reardon W, Byers PH, Lapiere CM, Prockop DJ, Nusgens BV: Human Ehlers-Danlos syndrome type VII C and bovine dermatosparaxis are caused by mutations in the procollagen I Nproteinase gene. Am J Human Genetics 1999, 65(2):308-17.

131. Dagoneau N, Benoist-Lasselin C, Huber C, Faivre L, Megarbane A, Alswaid A, Dollfus H, Alembik Y, Munnich A, Legeai-Mallet L, Cormier-Daire V: ADAMTS10 mutations in autosomal recessive Weill-Marchesani syndrome. Am J Human Genetics 2004, 75(5):801-6.

132. Gould D, Pettitt L, McLaughlin B, Holmes N, Forman O, Thomas A, Ahonen S, Lohi H, O'Leary C, Sargan D, Mellersh C: ADAMTS17 mutation associated with primary lens luxation is widespread among breeds. Veterinary Ophthalmol 2011, 14:1-7.

133. Barnett KC, Sansom J, Heinrich C: Glaucoma. In Canine Ophthalmology An Atlas and Text. Edited by Gregory J. Harcourt Publishers Limited; 2002:99-107.

134. Bjerkas E, Ekesten B, Farstad W: Pectinate ligament dysplasia and narrowing of the iridocorneal angle associated with glaucoma in the English Springer Spaniel. Veterinary Ophthalmol 2002, 5(1):49-54.

135. Gelatt KN, MacKay EO: Prevalence of the breed-related glaucomas in pure-bred dogs in North America. Veterinary Ophthalmol 2004, 7(2):97-111.

136. Oshima Y, Bjerkas E, Peiffer RL Jr: Ocular histopathologic observations in Norwegian Elkhounds with primary open-angle, closed-cleft glaucoma. Veterinary Ophthalmol 2004, 7(3):185-8.

137. Wyman M, Ketring K: Congenital glaucoma in the basset hound: a biologic model. Trans Sect Ophthalmol Am Acad Ophthalmol Otolaryngol 1976, 81 (4 Pt 1):OP645-52.

138. Wood JL, Lakhani KH, Mason IK, Barnett KC: Relationship of the degree of goniodysgenesis and other ocular measurements to glaucoma in Great Danes. Am J Veterinary Res 2001, 62(9):1493-9.
139. Wood JL, Lakhani KH, Read RA: Pectinate ligament dysplasia and glaucoma in flat coated retrievers. II. assessment of prevalence and heritability. Veterinary Ophthalmol 1998, 1(2-3):91-99.

140. Read RA, Wood JL, Lakhani KH: Pectinate ligament dysplasia (PLD) and glaucoma in Flat Coated Retrievers. I. Objectives, technique and results of a PLD survey. Veterinary Ophthalmol 1998, 1(2-3):85-90.

141. Ahonen SJ, Pietila E, Mellersh CS, Tiira K, Hansen L, Johnson GS, Lohi H: Genome-wide association study identifies a novel canine glaucoma locus. PLOS ONE 2013, 8(8):e70903.

142. Gelatt KN, Gum GG: Inheritance of primary glaucoma in the beagle. Am J Veterinary Res 1981, 42(10):1691-3.

143. Gelatt KN, Gum GG, Gwin RM, Bromberg NM, Merideth RE, Samuelson DA: Primary open angle glaucoma: inherited primary open angle glaucoma in the beagle. Am J Pathol 1981, 102(2):292-5.

144. Gelatt KN, Gwin RM, Peiffer RL Jr, Gum GG: Tonography in the normal and glaucomatous beagle. Am J Veterinary Res 1977, 38(4):515-20.

145. Gelatt KN, Peiffer RL Jr, Gwin RM, Gum GG, Williams LW: Clinical manifestations of inherited glaucoma in the beagle. Invest Ophthalmo Vis Sci 1977, 16(12):1135-42.

146. Mackay EO, Kallberg ME, Gelatt KN: Aqueous humor myocilin protein levels in normal, genetic carriers, and glaucoma Beagles. Veterinary Ophthalmol 2008, 11(3):177-85.

147. Kuchtey J, Olson LM, Rinkoski T, Mackay EO, Iverson TM, Gelatt KN, Haines $J$, Kuchtey RW: Mapping of the disease locus and identification of ADAMTS10 as a candidate gene in a canine model of primary open angle glaucoma. PLoS Genet 2011, 7(2):e1001306.

148. Curtis R, Barnett KC, Leon A: Persistent hyperplastic primary vitreous in the Staffordshire bull terrier. Vet Rec 1984, 115(15):385.

149. Leon A, Curtis R, Barnett KC: Hereditary Persistent Hyperplastic Primary Vitreous in the Staffordshire Bull Terrier. J Am Animal Hospital Assoc 1986, 22:765-774

150. Stades FC, Boeve MH, van den Brom WE, van der Linde-Sipman JS: The incidence of PHTVL/PHPV in Doberman and the results of breeding rules. Vet Q 1991, 13(1):24-9

doi:10.1186/2052-6687-1-3

Cite this article as: Mellersh: The genetics of eye disorders in the dog.

Canine Genetics and Epidemiology 2014 1:3.

\section{Submit your next manuscript to BioMed Central and take full advantage of:}

- Convenient online submission

- Thorough peer review

- No space constraints or color figure charges

- Immediate publication on acceptance

- Inclusion in PubMed, CAS, Scopus and Google Scholar

- Research which is freely available for redistribution 